\title{
Enforced covalent trimerization increases the activity of the TNF ligand family members TRAIL and CD95L
}

\author{
D Berg ${ }^{1,4}$, M Lehne ${ }^{1,4}$, N Müller ${ }^{1}$, D Siegmund ${ }^{1}$, S Münkel ${ }^{2}$, W Sebald ${ }^{3}$, K Pfizenmaier ${ }^{2}$ and H Wajant ${ }^{\star}, 1$
}

Variants of human TRAIL (hTRAIL) and human CD95L (hCD95L), encompassing the TNF homology domain (THD), interact with the corresponding receptors and stimulate CD95 and TRAILR2 signaling after cross-linking. The murine counterparts (mTRAIL, $\mathrm{mCD} 95 \mathrm{~L}$ ) showed no or only low receptor binding and were inactive/poorly active after cross-linking. The stalk region preceding the THD of mCD95L conferred secondary aggregation and restored CD95 activation in the absence of cross-linking. A corresponding variant of mTRAIL, however, was still not able to activate TRAIL death receptors, but gained good activity after cross-linking. Notably, disulfide-bonded fusion proteins of the THD of mTRAIL and mCD95L with a subdomain of the tenascin-C (TNC) oligomerization domain, which still assembled into trimers, efficiently interacted with their cognate cellular receptors and robustly stimulated CD95 and TRAILR2 signaling after secondary cross-linking. Introduction of the TNC domain also further enhanced the activity of THD encompassing variants of hTRAIL and hCD95L. Thus, spatial fixation of the N-terminus of the THD appears necessary in some TNF ligands to ensure proper receptor binding. This points to yet unanticipated functions of the stalk and/or transmembrane region of TNF ligands for the functionality of these molecules and offers a broadly applicable option to generate recombinant soluble ligands of the TNF family with superior activity.

Cell Death and Differentiation (2007) 14, 2021-2034; doi:10.1038/sj.cdd.4402213; published online 17 August 2007

Ligands of the tumor necrosis factor (TNF) family fulfill crucial roles in the immune system, but have also been implicated in the development of epithelial and endothelial structures. ${ }^{1}$ TNF family ligands are primarily expressed as trimeric type II transmembrane proteins and are often processed into soluble variants that are also organized as trimers. ${ }^{1,2}$ Although shedding of some TNF ligands does not interfere with their capability to activate their corresponding receptors and might be even important for their physiological function, other TNF ligands become inactivated by proteolytic processing. ${ }^{2}$ Soluble TNF ligands that are not or only poorly active still interact with their cognate receptors. For example, the soluble forms of TNF, CD95L, TRAIL, and CD40L interact with TNFR2, CD95, TRAILR2, and CD40, respectively, but do not or only poorly activate signaling by these receptors. ${ }^{3-6}$ Notably, inactive or poorly active soluble TNF ligands can be converted into highly active molecules by artificially increasing their avidity. For example, soluble flag-tagged variants of TNF, CD95L, TRAIL, and CD40L stimulate robust signaling by TNFR2, CD95, TRAILR2, and CD40, respectively, provided they were cross-linked with the Flag-specific mAb M2. Likewise, hexameric and dodecameric fusion proteins of soluble CD95L and soluble CD40L as well as non-specifically aggregated preparations of TNF ligands produced in E. coli display high activity. ${ }^{6-8}$

The structural hallmark of the ligands of the TNF family is the carboxy-terminal 'TNF homology domain', which is part of both the transmembrane and soluble forms of TNF ligands. ${ }^{1-2}$ The TNF homology domains (THDs) of the various TNF ligands are composed of a framework of aromatic and hydrophobic residues that adopt an almost identical tertiary fold and cause self association into trimers. ${ }^{1-2}$ The THD also mediates receptor binding. In general, trimeric ligands of the TNF family bind to three molecules of their corresponding receptor(s). This interaction alone is not necessarily sufficient to activate receptor-associated intracellular signaling pathways. Several lines of evidence suggest that the initial formation of trimeric signaling competent ligand receptor complexes is followed by secondary multimerization into supramolecular clusters. ${ }^{9-11}$ These two steps in TNF receptor activation (1. ligand binding; 2 . secondary aggregation of receptor ligand complexes) depend to a varying extent on several factors including lipid raft localization, cytoskeleton support, receptor auto-aggregation, receptor associated adapter proteins, but also on affinity and avidity of the ligand receptor interaction and the way how the ligand

\footnotetext{
${ }^{1}$ Department of Molecular Internal Medicine, Medical Clinic and Polyclinic II, University of Wuerzburg, Wuerzburg 97070, Germany; ${ }^{2}$ Institute of Cell Biology and Immunology, University of Stuttgart, Stuttgart 70569, Germany and ${ }^{3}$ Theodor-Boveri-Institute for Biosciences, Physiological Chemistry II, University of Wuerzburg, Wuerzburg 97074, Germany

${ }^{*}$ Corresponding author: $\mathrm{H}$ Wajant, Department of Molecular Internal Medicine, Medical Clinic and Polyclinic II, University of Wuerzburg, Roentgenring 11, Wuerzburg 97070, Germany. Tel: + 49931201 71010; Fax: + 49931201 71070; E-mail: harald.wajant@ mail.uni-wuerzburg.de

${ }^{4}$ These authors contributed equally to this work.

Keywords: CD95L; TRAIL; TNF homology domain

Abbreviations: BSA, bovine serum albumin; $\mathrm{BS}^{3}$, bis(sulfosuccinimidyl)suberate; CD95L, CD95-ligand; CD40L, CD40-ligand; CHX, cycloheximide; DISC, deathinducing signaling complex; ELISA, enzyme-linked immunosorbent assay; FCS, fetal bovine serum; FLIP, FLICE-inhibitory protein; MTT, (3-(4,5-dimethylthiazol-2-yl)-2, 5-diphenyltetrazolium bromide; PBS, phosphate-buffered saline; PE, phycoerythrin; SDS-PAGE, sodium dodecylsulfate polyacrylamide gel electrophoresis; THD, TNF homology domain; TNC, tenascin-C; TNF, tumor necrosis factor; TRAIL, TNF-related apoptosis inducing ligand; TRAILR1/2/4, TRAIL-receptor 1/2/4; ZVAD, z-Val-AlaDL-Asp-fluoromethylketon

Received 25.10.06; revised 07.6.07; accepted 15.6.07; Edited by J Tschopp; published online 17.8.07
} 
is presented to the receptor (membrane ligand or immobilized ligand versus soluble ligand, trimers versus higher aggregates).

Here we show that soluble variants of murine CD95L (mCD95L) and murine TRAIL (mTRAIL), solely containing the THD in contrast to their human counterparts, practically do not bind to their corresponding receptors. In accordance with the observed differences in receptor binding, the human, but not the murine ligands, strongly activated CD95 and TRAILR2 after secondary cross-linking. Importantly, fusion proteins of the murine ligands with a small domain of tenascin- $C$ (TNC), forming disulfide bridge-connected trimers, did not aggregate secondarily, but displayed restored receptor binding and strong cross-linking-dependent receptor activation. The activity of secondarily aggregated human TRAIL (hTRAIL) and human CD95L (hCD95L) were also further enhanced by fusion with the TNC domain. Thus, we identified enforced covalent trimerization as a powerful means to increase the activity and stability of some members of the TNF ligand family.

\section{Results and Discussion}

Soluble variants of $\mathrm{mCD}$ 95L and $\mathrm{mTRAIL}$ are practically inactive even after cross-linking. Amino terminally Flag-tagged variants of human and murine CD95L and TRAIL containing the THD (aa 137-281 of hCD95L, aa 137279 of mCD95L, aa 95-291 of hTRAIL, aa 99-291 of mTRAIL) were transiently produced in HEK293 cells and purified from the supernatants by affinity chromatography on anti-flag mAb M2 agarose (Figure 1 and 2a). Both FlaghCD95L (137-281) and Flag-mCD95L (137-279) migrated in SDS-PAGE analysis as intense doublets with deduced
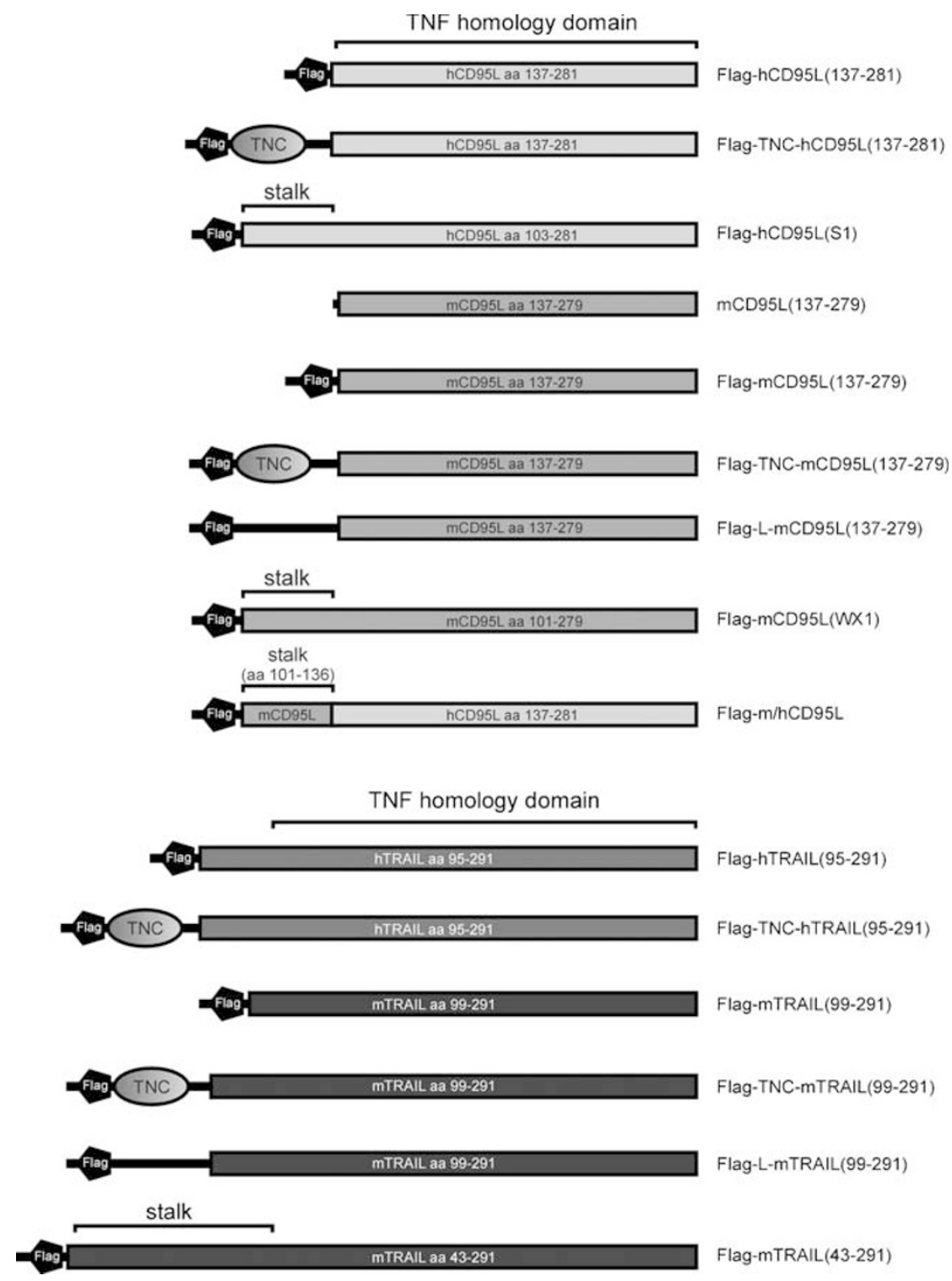

Figure 1 Domain architecture of the various CD95L and TRAIL variants used in this study. TNC,trimerization domain of chicken TNC (aa 110-139), Flag,Flag epitope (DYKDDDDK). The stalk region refers to the structural less defined part between the transmbembrane domain and the TNF homolgy domain of the various ligands 
a

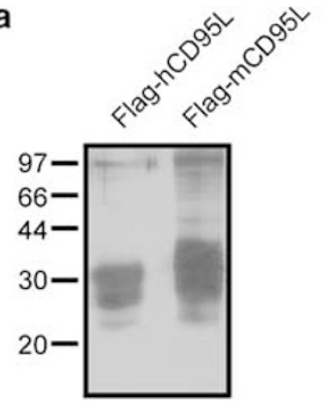

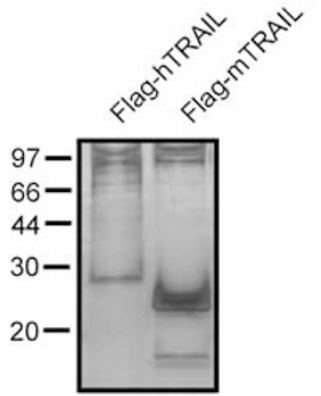

b
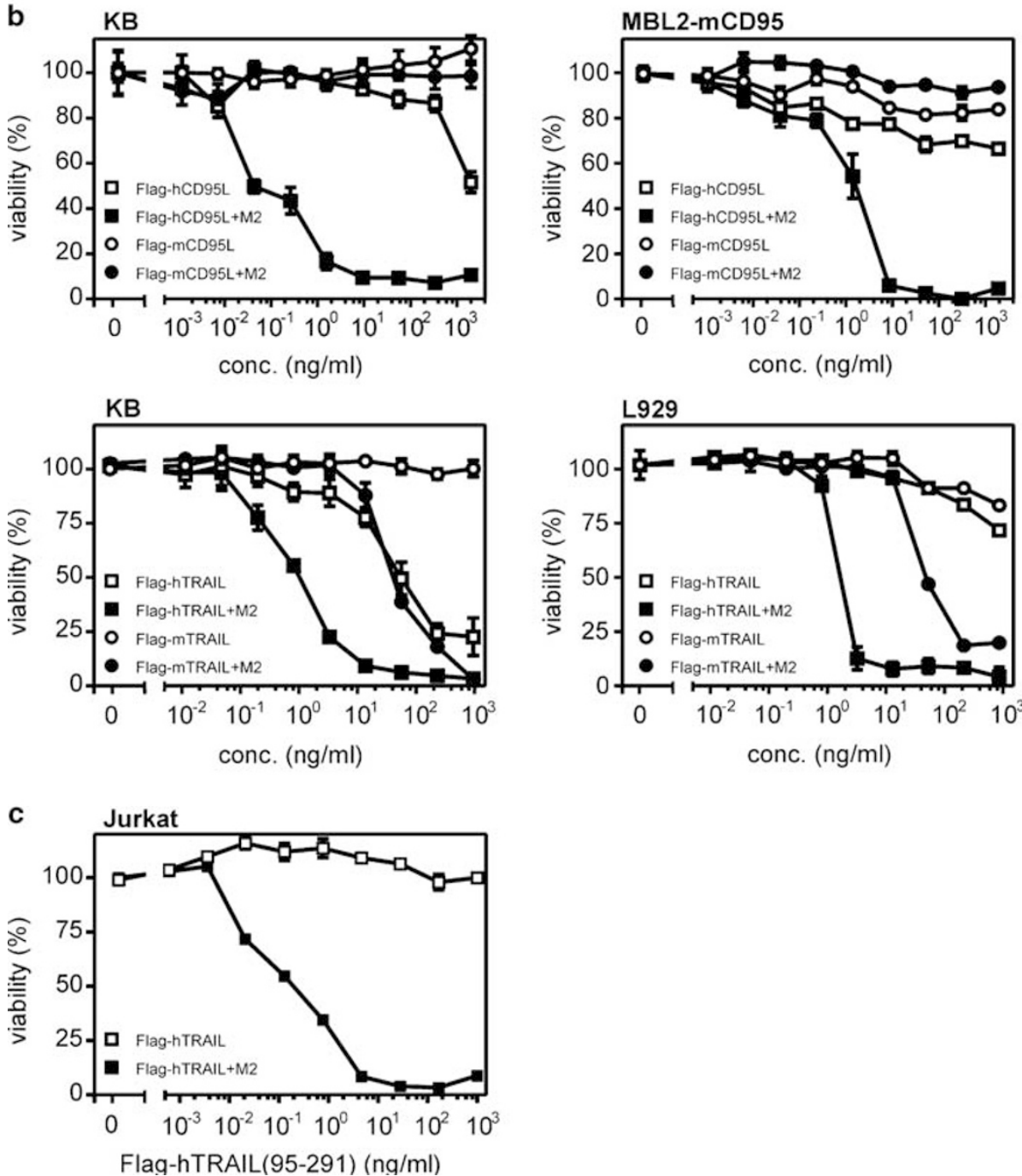

Figure 2 Soluble variants of mCD95L and mTRAIL encompassing solely the THD are practically inactive. (a) Soluble, N-terminally Flag-tagged variants of hCD95L (Flag-hCD95L(137-281)), mCD95L (Flag-mCD95L(137-279)), hTRAIL (Flag-hTRAIL(95-291)), and mTRAIL (Flag-mTRAIL(99-291)) encompassing the THD were produced in HEK293 cells, purified by M2 affinity chromatography and analyzed by SDS-PAGE and silver staining. Migration positions of molecular mass markers (in kDa) are indicated on the left margin. (b) KB cells (human origin), L929 (murine origin), and mCD95-expressing MBL2 transfectants (murine origin) were seeded in triplicates in 96-well plates. The next day, cells (KB, L929) were sensitized for cell death induction by treatment with $2.5 \mu \mathrm{g} / \mathrm{ml}$ CHX and were then stimulated (KB, L929, MBL2-CD95) with the indicated concentrations of Flag-mCD95L(137-279) (KB, MBL2-CD95), Flag-hCD95L(137-281) (KB, MBL2-CD95), Flag-hTRAIL(95-291) (KB, L929), and Flag-mTRAIL(99-291) (KB, L929) in the presence and absence of anti-Flag mAb M2 (CD95L variants: $0.5 \mu \mathrm{g} / \mathrm{ml}$; TRAlL variants $3 \mu \mathrm{g} / \mathrm{ml}$ ). Cell viability was determined by crystal violet staining. (c) Jurkat cells were challenged in triplicates in 96-well plates with the indicated concentration of Flag-hTRAIL(95-291) or M2-crosslinked Flag-hTRAIL(95-291). Cell viability was determined using the MTT assay

molecular masses between 24 and $30 \mathrm{kDa}$. In addition, a minor fraction of both proteins also migrated at $21 \mathrm{kDa}$ (Figure 2a). These values significantly exceed the calculated mass of $17 \mathrm{kDa}$ for both Flag-hCD95L(137-281) and FlagmCD95L(137-279). The heterogeneity and discrepancy between calculated and observed molecular mass is in 
good accordance with the fact that CD95L can be glycosylated at three asparagine residues in the THD, since one $\mathrm{N}$-linked carbohydrate accounts for $2-3 \mathrm{kDa}$ by SDS-PAGE. ${ }^{12}$ Flag-hCD95L(137-281) poorly killed human KB cells and murine MBL2-CD95 transfectants cells $\left(E D_{50}>1000 \mathrm{ng} / \mathrm{ml}\right)$, but readily killed both cell lines after secondary cross-linking via its Flag-tag $\left(E D_{50}=0.1-1 \mathrm{ng} / \mathrm{ml}\right)$. In contrast, the corresponding Flag-tagged mCD95L(137279) variant practically induced cell death in neither KB nor in MBL2-CD95 cells despite cross-linking (Figure $2 b$ ). A related activity pattern was observed with human and mTRAIL. Both molecules induced less than $25 \%$ killing on L929 cells, even at concentrations of $1000 \mathrm{ng} / \mathrm{ml}$. While Flag-hTRAIL(95-291) significantly induced cell death in these cells with $1 \mathrm{ng} / \mathrm{ml}$ after secondary cross-linking via the Flag-tag contained in the molecule, Flag-mTRAIL(99-291) was approximately 50-fold less active after secondary aggregation (Figure $2 b$ ). Further, Flag-hTRAIL(95-291) killed KB cells without crosslinking, starting at concentrations of $10 \mathrm{ng} / \mathrm{ml}$, while noncrosslinked Flag-mTRAIL(99-291) showed no activity at all up to $1000 \mathrm{ng} / \mathrm{ml}$ (Figure 2b). Cross-linking with anti-Flag further enhanced the activity of the hTRAIL variant and also allow killing by the murine counterpart at higher concentrations (Figure 2b). The differential effect of noncrosslinked hTRAIL on KB and L929 cells can be explained by earlier findings demonstrating that TRAILR2 is much more better activated by secondary cross-linked trimers of soluble TRAIL than by non-crosslinked molecules, whereas TRAILR1 is stimulated with the same efficiency by crosslinked and non-crosslinked TRAIL. $5,13,14$ Thus, in KB cells that express TRAILR1 and TRAILR2, non-crosslinked TRAIL trimers already significantly induce cell death via the TRAILR1, whereas TRAILR1-mediated cell death is not relevant in the murine L929 cell line, because in mice only a homolog of human TRAILR2 exists. ${ }^{15,16}$ In fact, in human Jurkat cells, which express only TRAILR2, noncrosslinked Flag-hTRAIL(95-291) is also practically inactive (Figure 2c).

The THD of mCD95L and mTRAIL is not sufficient to allow receptor binding. Next, we analyzed binding of the various recombinant ligands to cells using FACS analysis. KB, MBL2-CD95, and L929 cells were incubated with increasing concentrations of the TRAIL and CD95L variants on ice and after removal of unbound molecules, cell associated ligands were detected using anti-Flag mAb M2 and a PE-labeled secondary antibody. Significant binding of Flag-hCD95L(137-281) to human and murine CD95 was observed down to concentrations of 0.3 and $0.1 \mu \mathrm{g} / \mathrm{ml}$ and significant binding of Flag-hTRAIL(95-291) to human and mTRAIL receptors was observed starting with concentrations of 40 and $600 \mathrm{ng} / \mathrm{ml}$, respectively. In contrast, murine CD95L showed no binding even when concentrations upto 5 or $10 \mu \mathrm{g} / \mathrm{ml}$ were used and mTRAIL exerted only weak binding on L929 cells and no binding on KB cells (Figure 3a). Binding of the murine ligands were also not significantly changed when they were preincubated with the M2 antibody before FACS staining (data not shown). To exclude the possibility that the Flag-tag, which is highly charged, specifically prevented receptor binding of Flag-tagged proteins, we also analyzed a non-tagged variant of mCD95L (Figure 3b). Owing to the lack of the Flag epitope, we were unable to analyze receptor binding of $\mathrm{mCD} 95 \mathrm{~L}(137-279)$ directly by FACS. Instead, we performed a competition assay, in which the capacity of the non-tagged ligand to protect against cell death induction was determined using a highly active hexameric fusion protein of hCD95L (Fc-hCD95L) and the Fc domain of human IgG1 (see Holler et al. ${ }^{7}$ ) was determined. While preincubation of $\mathrm{KB}$ cells with $50 \mathrm{ng} / \mathrm{ml}$ Flag-hCD95L(137-281) was sufficient to rescue about half of the cells from Fc-hCD95L-induced cell death, the non-tagged mCD95L(137-279) failed even at high concentrations $(1 \mu \mathrm{g} / \mathrm{ml})$ to show a protective effect (Figure 3c). We also performed surface plasmon resonance analysis, using an immobilized chimeric protein consisting of the extracellular domain of human CD95 fused to the constant region of human IgG1 and Flag-hCD95L(137-281), Flag-mCD95L (137-279) or Flag-TNC-mCD95L(137-279) in solution. For Flag-TNC-mCD95L(137-279) and Flag-hCD95L(137-281), we obtained dissociation constants of 26 and $39 \mathrm{nM}$. With Flag-mCD95L(137-279) non-specific binding was observed even at concentration of $2000 \mathrm{nM}$ (Figure 3d). Together, our data indicate that the receptor binding of both murine nontagged ligand variants is negligible. A possible explanation for the inability/poor ability of Flag-mCD95L(137-279) and Flag-mTRAIL(99-291) to interact with their corresponding receptors is that the THDs of these molecules, determined by sequence homology with their human counterparts, are not sufficient to drive ligand trimerization. We therefore, investigated the various recombinant ligands by chemical cross-linking and gel filtration. Treatment of Flag-hCD95L (137-281) and Flag-hTRAIL(95-291) with increasing concentrations of the homobifunctional cross-linker $\mathrm{BS}^{3}$ allowed, as expected, the identification of dimers and trimers (Figure 4a). Notably, cross-linking of the murine ligands lead to formation of dimeric and trimeric adducts with a similar $\mathrm{BS}^{3}$ dose dependency as observed with their human counterparts (Figure 4a). Thus, there was no evidence from the cross-linking experiments for a differential capability of murine and human ligands to organize into trimers. In gel filtration experiments, Flag-hCD95L(137-281) was eluted in one symmetric peak, which corresponds in size to a molecular mass of about $72 \mathrm{kDa}$ (Table 1, Figure 4b) in good agreement with a trimeric organization of the glycosylated molecule in solution. The hCD95L preparation obtained after gel filtration still interacted with CD95 and showed normal activity after secondary cross-linking (data not shown). Flag-mCD95L(137-279) was eluted in a highmolecular-weight (MW) peak, a second peak with an elution volume comparable to that of Flag-hCD95L(137-281) trimers $(85 \mathrm{kDa})$ and a third peak corresponding in size to a monomer (31 kDa) (Figure 4b). As expected Flag-mCD95L (137-279) derived of each of these peaks was inactive even after cross-linking with the anti-Flag mAb M2 (Table 1). Thus, the high-molecular-weight Flag-mCD95L(137-279) fractions obviously represented misfolded inactive ligand aggregates rather than activated secondary aggregates of latently active ligand trimers. A similar picture emerged when the various TRAIL variants were analyzed by gel filtration. In all cases, there was a peak corresponding in size to MWs of $75-125 \mathrm{kDa}$ 

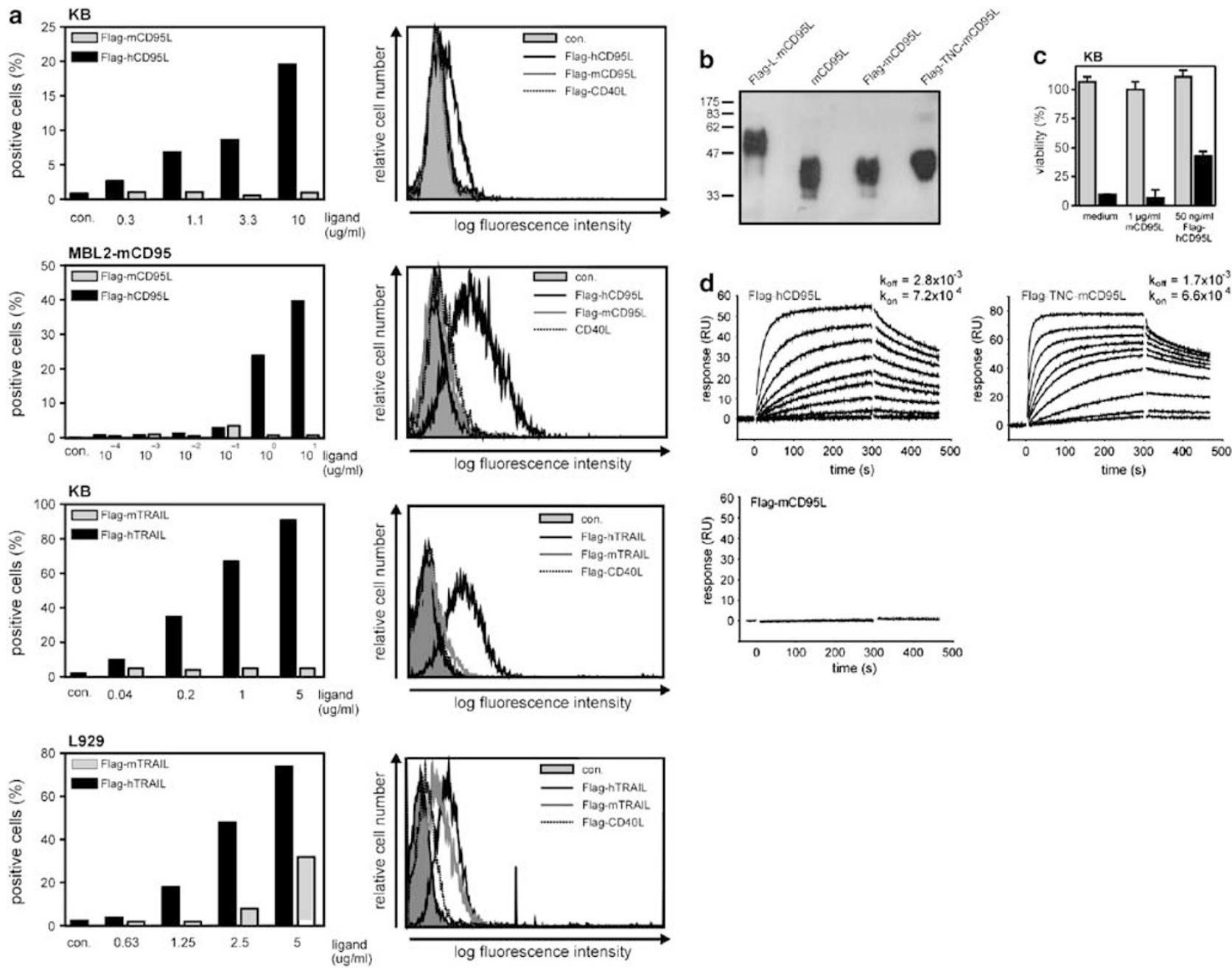

Figure 3 Soluble variants of mCD95L and mTRAIL encompassing the THD do not bind to their corresponding cellular receptors. (a) The indicated cell lines were incubated with varying concentrations of Flag-mCD95L (137-279) (KB, MBL2-CD95), Flag-hCD95L(137-281) (KB, MBL2-CD95), Flag-hTRAIL(95-291) (KB, L929), and Flag-mTRAIL (99-291) (KB, L929) on ice and after repeated washes, bound proteins were detected by FACS using anti-Flag mAb M2 and PE-labeled anti mouse IgG. A soluble N-terminally Flag-tagged variant of human CD40L was used as a control. Left panel shows percent positive gated cells and the right panel show histograms of samples treated with the highest ligand concentration. (b) Cell culture supernatants containing $50 \mathrm{ng}$ of the indicated proteins were analyzed by western blotting, using primary antibodies specific for mCD95L. (c) KB cells were pretreated for $1 \mathrm{~h}$ in triplicates with the indicated reagents. Subsequently, cells were cultured overnight in the presence (black bars) or absence (gray bars) of Fc-hCD95L. Finally, cell viability was determined using the MTT assay (Jurkat) or crystal violet staining (KB). (d) The indicated CD95L variants were analyzed by surface plasmon resonance using BIAcore 2000 and a streptavidin sensor chip coated with biotinylated Fc-CD95. Sensorgrams for binding of the mCD95L variants are shown for concentrations of 5000, 2000, 1000,500, 300, 200, 100, 30, and $5 \mathrm{nM}$. Flag-hCD95L sensorgrams are shown for concentrations of 1000, 400, 200, 100, 60, 40 20, 6, and $2 \mathrm{nM}$. The indicated values for $k_{\text {off }}$ and $k_{\text {on }}$ were determined, using a $1: 1$ binding model and the software supplied by the manufacturer for 1000 and were averaged from the plots between 1000 and $20 \mathrm{nM}$ (hCD95L) and 2000 and $30 \mathrm{nM}$ (murine CD95L variants)

and thus to a timeric organization of the corresponding molecules (Table 1, Figure 4b). In addition, we did also observe a second high MW peak containing inactive TRAIL aggregates (Table 1). Flag-mTRAIL(99-291) was further found in an additional peak, corresponding in size roughly to a monomer.

Covalent stabilization of the trimeric structure of mCD95L and mTRAIL restores receptor binding and cross-linking-dependent activity. So far our data demonstrated that the trimerization of the THD alone is not necessarily sufficient to ensure proper receptor binding. This suggests that especially in the case of mCD95L and mTRAIL additional structural cues located outside of the THD are required to enable these molecules to bind their cognate receptors. In this regard, the THDs of CD95L and TRAIL are separated from their transmembrane domains by a stalk region. In fact, Nagata and co-workers have shown that a variant of mCD95L (named WX1) comprising aa 101-279 and thus containing the stalk region is biologically active. ${ }^{17}$ It is note worthing, Flag-mCD95L(WX1) is already active without secondary cross-linking and organizes to about $50 \%$ in oligomers instead of trimers (Table 1 Figure 1,4 and 5a). Moreover, secondary cross-linking of the Flag-tagged variant of WX1 did not further enhance the activity of the molecule (Figure 5a). The Flag-tagged human counterpart of the 

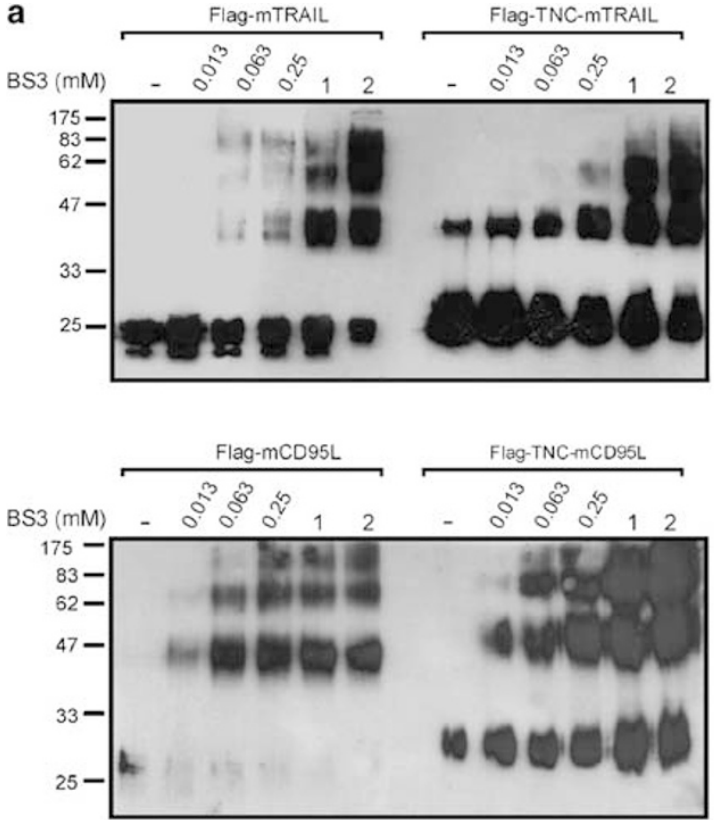
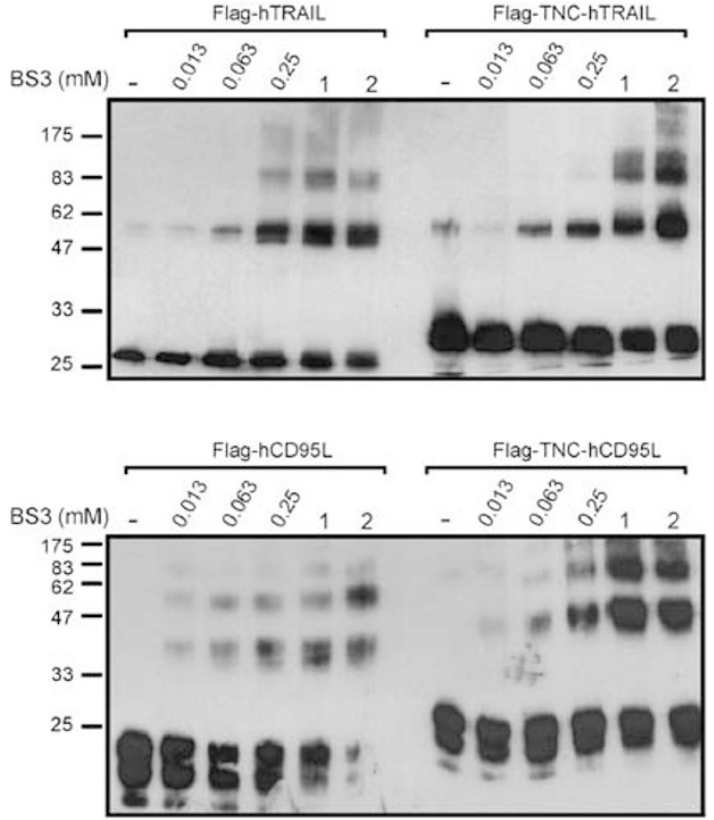

b

0
0
0
0
$\frac{0}{0}$
0
0
0
0

BioSep-SEC-S3000

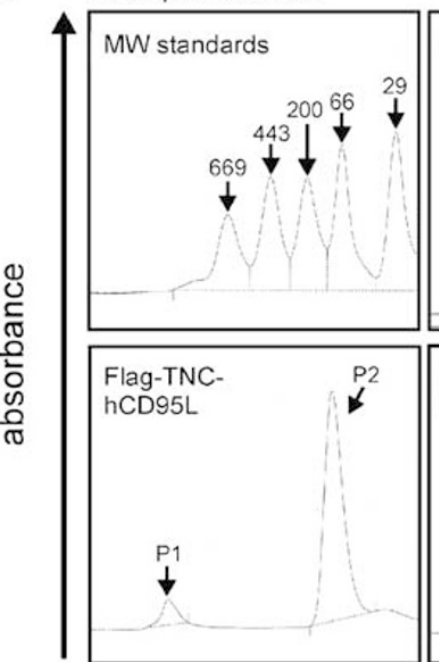

Flag-hCD95L
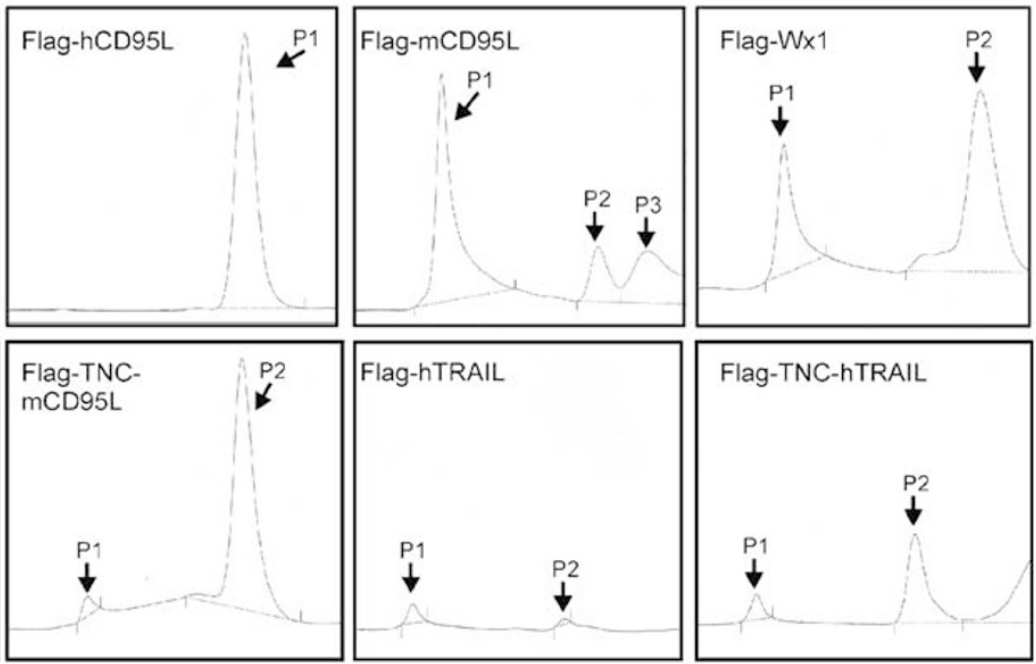

elution volume

BioSep-SEC-S2000

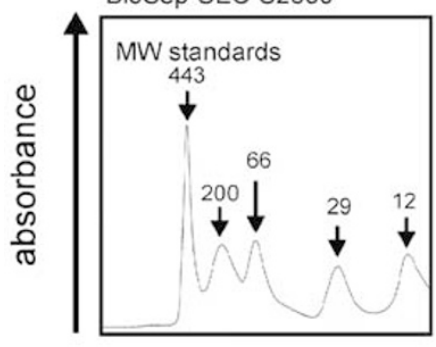

Flag-mTRAIL

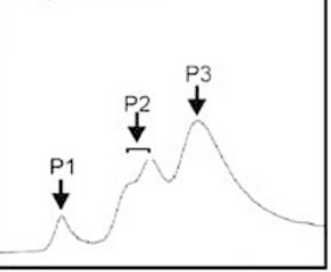

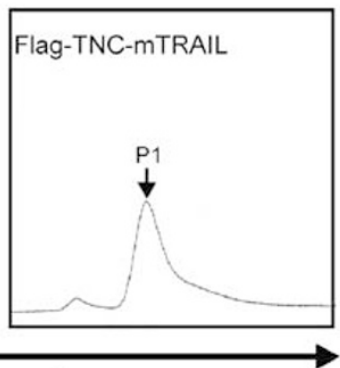

elution volume

Figure 4 Soluble variants of CD95L and TRAIL of human and murine origin as well as their corresponding TNC-fusion proteins assemble into trimers. (a) The indicated proteins were treated with the increasing concentrations of the chemical cross-linker $\mathrm{BS}^{3}$ on ice for $1 \mathrm{~h}$ and were analyzed under reducing conditions by Western Blot using the anti-Flag mAb M2. Migration positions of molecular mass markers (in $\mathrm{kDa}$ ) are indicated at the left margin. (b) The indicated proteins were separated by gel filtration chromatography using a BioSep-SEC-S3000 (upper panel) or a BioSep-Sec-S2000 column. The following molecular mass markers were used: thyroglobulin (669 kDa), apoferritin $(443 \mathrm{kDa}), \beta$-amylase $(200 \mathrm{kDa})$, serum albumin $(66 \mathrm{kDa})$, carbonic anhydrase $(29 \mathrm{kDa})$, and cytochrome $c(12.4 \mathrm{kDa})$ 
Table 1 Gel filtration analysis of recombinant TRAIL and CD95L variants

\begin{tabular}{|c|c|c|c|c|c|}
\hline \multirow[t]{2}{*}{ Protein } & \multirow[t]{2}{*}{ MW kDa } & \multirow[t]{2}{*}{ Peak area $\mathbf{m V} \times \mathbf{s}$} & \multirow[t]{2}{*}{ FACS binding } & Activity no M2 & Activity+M2 \\
\hline & & & & \multicolumn{2}{|c|}{ dilution of ED50 } \\
\hline $\begin{array}{l}\text { Flag-mCD95L(137-279) } \\
\quad \text { Peak } 1 \\
\text { Peak } 2 \\
\text { Peak } 3\end{array}$ & $\begin{array}{l}\text { HWA } \\
86 \\
32\end{array}$ & $\begin{array}{l}463 \\
109 \\
224\end{array}$ & $\begin{array}{l}\text { no } \\
\text { no } \\
\text { no }\end{array}$ & $\begin{array}{l}\text { no } \\
\text { no } \\
\text { no }\end{array}$ & $\begin{array}{l}\text { no } \\
\text { no } \\
\text { no }\end{array}$ \\
\hline $\begin{array}{l}\text { Flag-TNC-mCD95L(137-279 } \\
\quad \text { Peak } 1 \\
\text { Peak } 2\end{array}$ & $\begin{array}{l}\text { HWA } \\
128\end{array}$ & $\begin{array}{r}14 \\
380\end{array}$ & $\begin{array}{l}\text { weak } \\
\text { yes }\end{array}$ & $\begin{array}{l}\ll 1 \\
\ll 360\end{array}$ & $\begin{array}{l}\ll 1 \\
12960\end{array}$ \\
\hline Flag-hCD95L(137-281) & 72 & 692 & yes & $\ll 60$ & 12960 \\
\hline $\begin{array}{l}\text { Flag-TNC-hCD95L(137-281) } \\
\text { Peak } 1 \\
\text { Peak } 2\end{array}$ & $\begin{array}{l}\text { HWA } \\
104\end{array}$ & $\begin{array}{r}29 \\
337\end{array}$ & $\begin{array}{l}\text { n.d. } \\
\text { yes }\end{array}$ & $\begin{array}{l}\ll 1 \\
\ll 10\end{array}$ & $\begin{array}{l}\ll 1 \\
2160\end{array}$ \\
\hline $\begin{array}{l}\text { Flag-WX1 } \\
\text { Peak } 1 \\
\text { Peak } 2\end{array}$ & $\begin{array}{l}\text { HWA } \\
48\end{array}$ & $\begin{array}{r}93 \\
230\end{array}$ & $\begin{array}{l}\text { n.d. } \\
\text { n.d. }\end{array}$ & $\begin{array}{l}\text { n.d. } \\
\text { n.d. }\end{array}$ & $\begin{array}{l}\text { n.d. } \\
\text { n.d. }\end{array}$ \\
\hline $\begin{array}{l}\text { Flag-mTRAIL(99-291) } \\
\text { Peak } 1 \\
\text { Peak } 2 \\
\text { Peak } 3\end{array}$ & $\begin{array}{l}\text { HWA } \\
75-90 \\
35\end{array}$ & $\begin{array}{r}49 \\
184 \\
429\end{array}$ & $\begin{array}{l}\text { n.d. } \\
\text { n.d. } \\
\text { n.d. }\end{array}$ & $\begin{array}{l}\text { n.d. } \\
\ll 1 \\
\text { n.d. }\end{array}$ & $\begin{array}{l}\text { n.d. } \\
\ll 1 \\
\text { n.d. }\end{array}$ \\
\hline Flag-TNC-mTRAIL(99-291) & 85 & 192 & n.d. & active & active \\
\hline $\begin{array}{l}\text { Flag-hTRAIL(95-291) } \\
\quad \text { Peak } 1 \\
\text { Peak } 2\end{array}$ & $\begin{array}{l}\text { HWA } \\
125\end{array}$ & $\begin{array}{c}12 \\
2.7\end{array}$ & $\begin{array}{l}\text { n.d } \\
\text { n.d. }\end{array}$ & $\begin{array}{l}\ll 1 \\
4\end{array}$ & $\begin{array}{r}\ll 1 \\
100\end{array}$ \\
\hline $\begin{array}{l}\text { Flag-TNC-hTRAIL(95-291) } \\
\quad \text { Peak } 1 \\
\text { Peak } 2\end{array}$ & $\begin{array}{l}\text { HWA } \\
125\end{array}$ & $\begin{array}{r}18 \\
109\end{array}$ & $\begin{array}{l}\text { n.d } \\
\text { n.d. }\end{array}$ & $\begin{array}{l}\text { n.d. } \\
\text { active }\end{array}$ & $\begin{array}{l}\text { n.d. } \\
\text { active }\end{array}$ \\
\hline
\end{tabular}

$20 \mu \mathrm{l}$ of the various M2 agarose purified proteins were fractionated by gel filtration using a BioSep-SEC-S2000 (300 $\times 7.8)$ column (all CD95L variants, Flag-hTRAIL, Flag-TNC-hTRAIL) or a BioSep-SEC-S2000 $(300 \times 7.8)$ column (Flag-mTRAIL and Flag-TNC-mTRAIL). The columns were calibrated with thyroglobulin $(669 \mathrm{kDa})$, apoferritin $(443 \mathrm{kDa}), \beta$-amylase $(200 \mathrm{kDa})$, serum albumin $(66 \mathrm{kDa})$, carbonic anhydrase $(29 \mathrm{kDa})$ and cytochrome c (12.4 kDa). The molecular masses corresponding to the elution volumes of the various peaks were calculated using the linear regression of the logarithm of the molecular masses of the standards against their elution volume. Peaks were collected and analyzed as indicated with respect to the presence of the corresponding ligand by Western blot or ELISA, to binding and cell death induction in KB or L929 cells. The peak areas were automatically calculated by the FPLC software and indicate the relative amount of protein contained in the peak. To determine the capacity of proteins in the various peaks to induce cell death, the corresponding samples were titrated on $\mathrm{CHX}$ sensitized $\mathrm{KB}$ cells. The fold dilution sufficient to induced $50 \%$ killing was indicated. n.d. not determined. HWA, high molecular weight aggregates.

WX1 variant (named S1) showed also significant activity, which could be further moderately increased by secondary cross-linking (Table 1 Figure 1 and $5 \mathrm{~b}$ ). The specific activity of cross-linked Flag-hCD95L(S1) was roughly 100fold lower compared to cross-linked Flag-hCD95L(137-281) (Figure 5b). A chimeric ligand of the stalk region of $\mathrm{mCD} 95 \mathrm{~L}$ and the THD of hCD95L showed also a significant crosslinking independent capability to stimulate CD95 (Figure 5c). Flag-mTRAIL(43-291), a soluble mTRAIL variant containing the stalk region, showed a significant, but in comparison to Flag-hTRAIL(114-291) poor capability to induce cell death (Figure 5d). Of course, membrane mTRAIL was also able to stimulate TRAIL receptor signaling (Figure 5e). Together, these data suggest that the stalk region contained in some members of the TNF family, for example murine CD95L, has a ligand specific capability to facilitate the formation of secondary aggregated trimers. The different bioactivity of soluble ligand variants with and without stalk region might be explained by the concept that amino acids located outside the THD are required to make contact to their corresponding receptors, but it appeared also possible that the
THD of mTRAIL and mCD95L already contained latently all structural information required for receptor binding, but needed in addition spatial fixation and stabilization of their trimeric structure. In fact, a difference between soluble trimeric TRAIL and CD95L and their highly active membranebound counterparts is that the $\mathrm{N}$ terminus of the THD in the soluble molecules is practically free, whereas in the membrane-bound ligands the $\mathrm{N}$-terminal part of the THD is fixed by the transmembrane domain and/or the stalk region. To elucidate whether the improper receptor binding of stalkless $\mathrm{mCD}$ 95L and mTRAIL trimers was related to insufficient stability and spatial fixation of the THD of these molecules, we generated fusion proteins of these ligands in which the flexibility of the $\mathrm{N}$ termini was constrained by fusion to a small protein domain from chicken TNC forming covalently bound compact trimers (Figure 1). ${ }^{18}$ The TNC trimerization domain was chosen due to its small size of about only 30 aa. ${ }^{18}$ Anti-Flag affinity-purified TNC-Flag-mTRAIL(99-291) and Flag-TNC-mCD95L(137-279) migrated both in nonreducing SDS-PAGE analysis as trimers and showed in gel filtration analysis a comparable elution volume than the 

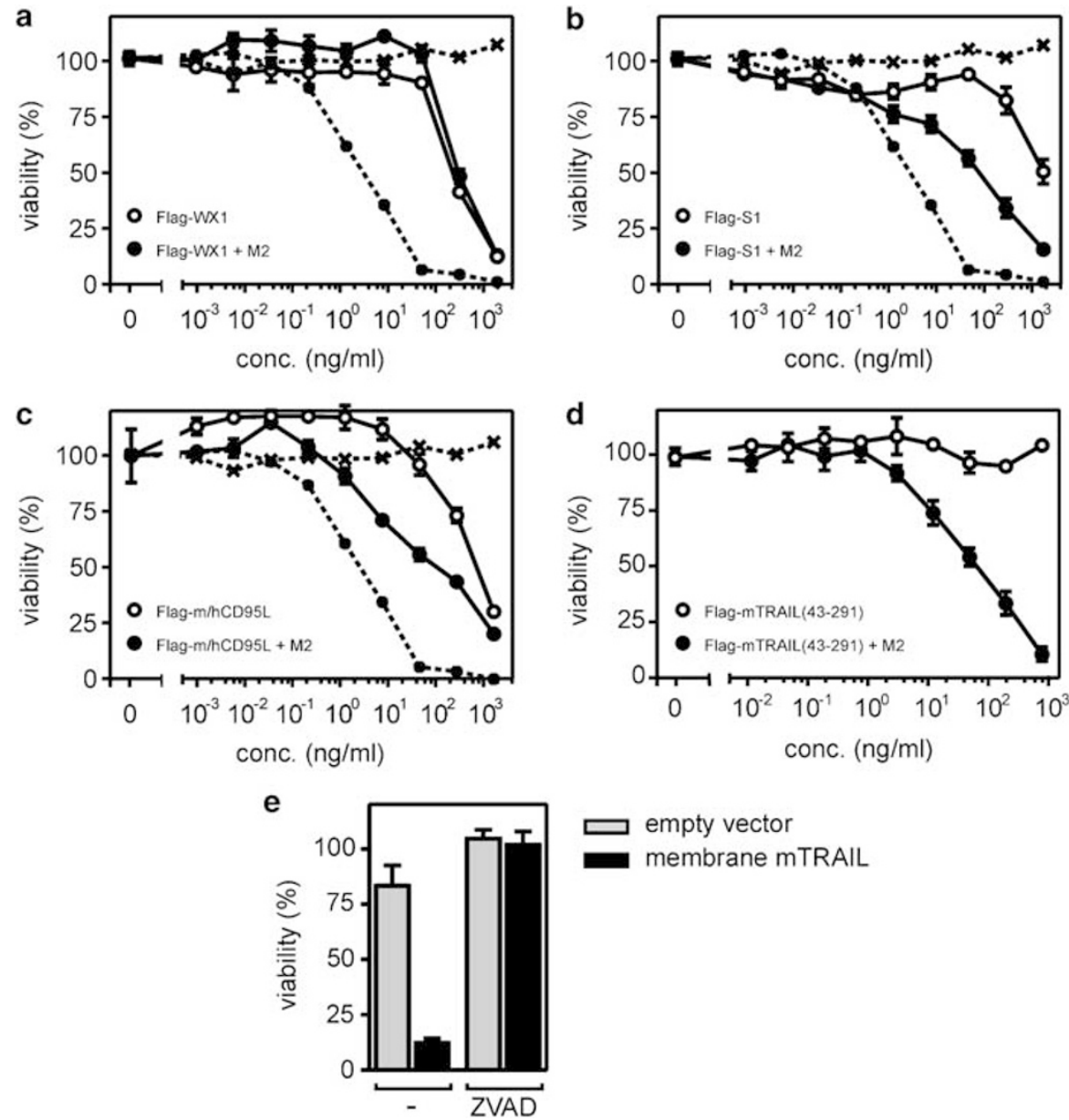

Figure 5 The stalk region of murine CD95L but not of mTRAIL is sufficient to convert the corresponding soluble ligands into an active variant. (a-e) KB cells were seeded in triplicates in 96-well plates. The following day, cells were stimulated with the indicated concentrations of M2-crosslinked or non-crosslinked Flag-mCD95L(WX1) (a), FlaghCD95L(S1) (b), Flag-m/hCD95L (c) and Flag-mTRAIL(43-291) (d) or with a 1:5 dilution of membrane mTRAIL containing lysates (e) in the presence of $2.5 \mu \mathrm{g} / \mathrm{ml}$ CHX. After $18 \mathrm{~h}$, cell viability was determined by crystal violet staining. To demonstrate that membrane TRAlL expressing cells undergo caspase-mediated cell death, the caspase inhibitor Z-Val-Ala-DL-Asp-fluoromethylketone was added $(20 \mu \mathrm{M})$. The cytotoxic effect of Flag-Flag-hCD95L(137-281) and M2-crosslinked Flag-hCD95L (137-281) was determined in parallel as a control and plotted in (a-c) (dotted lines, crosses: no cross-linking; asterisks: M2-cross-linking)

corresponding molecules without TNC domain (Figure 4a and $6 a$ and Table 1). These data showed first that the TNC part within the fusion proteins is still able to form disulfide bonds and indicated secondly that the serial arrangement of the trimerization domains of TNC and TNF ligands still results in the formation of trimers without evidence for a significant formation of high-MW aggregates. In further accordance with a trimeric organization of the TNC-fusion proteins and a lack of secondary aggregation, we detected after chemical cross-linking with increasing concentrations of the homobifunctional cross-linker $\mathrm{BS}^{3}$ preferentially dimers and trimers (Figure 4a). Thus, the THD of mCD95L and mTRAIL, irrespective of having a TNC domain or not, organizes into trimers. However, with respect to their functional properties the molecules behaved quite differently. As shown in Figure 3 Flag-mCD95L (137-279) and Flag-mTRAIL(99291) did not or only poorly interact with their cognate cellular receptors, but the TNC-fusion proteins showed effective binding in FACS analysis and resembled in this regard their human counterparts (Figure $6 \mathrm{~b}$ and $3 a$ ). Moreover, the murine TNC-fusion proteins are practically inactive despite receptor binding, but stimulated CD95 and TRAIL death receptor signaling after secondary cross-linking with high efficiency (Figure $6 \mathrm{c}$ ). To exclude the possibility that the improved receptor binding of the TNC variants is caused by the more distant position of the Flag epitope in TNCmCD95L(137-281) and Flag-TNC-mTRAIL(99-291) relative to the THD domain, rather than by the presence of the TNC domain, we generated ligand variants (Flag-L-mCD95L (137-279) and Flag-L-mTRAIL(99-291)) in which the Flag epitope was separated from the THD of the molecules via a linker corresponding in length to the TNC domain. We found that these ligand variants showed no (Flag-L-mCD95L(137279)) or only weak activity (Flag-L-mTRAIL(99-291)) without cross-linking. This suggests that the position of the Flag-tag relative to the THD domain of murine ligands has no major relevance for receptor binding of these molecules (Figure 6d). As the TNC domain is sufficient to recover the receptor binding capacity of the THD of $\mathrm{mCD} 95 \mathrm{~L}$ and mTRAIL, it is unlikely that specific amino acids located 
outside the THD are involved in direct interaction with the cognate receptors. Thus, spatial fixation of the $\mathrm{N}$-terminal part of the THD appears in some members of the TNF ligand family necessary to ensure proper receptor binding, for example by stabilizing the THD structure against structural disturbance related to receptor binding. Therefore, the stalk regions of CD95L and TRAIL can fulfill two functions: (i) stabilization of the THD, a function which can also be

a
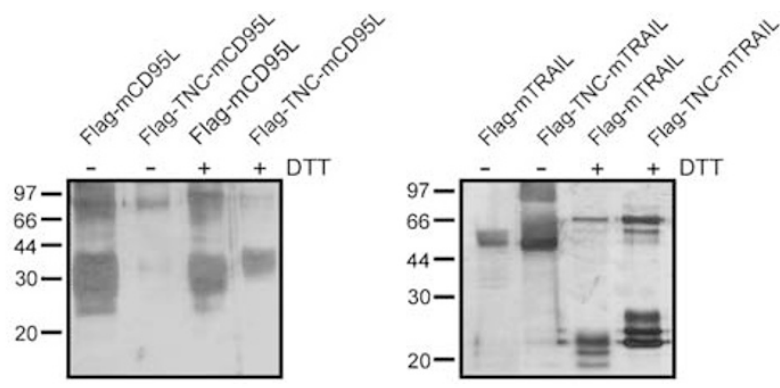

b
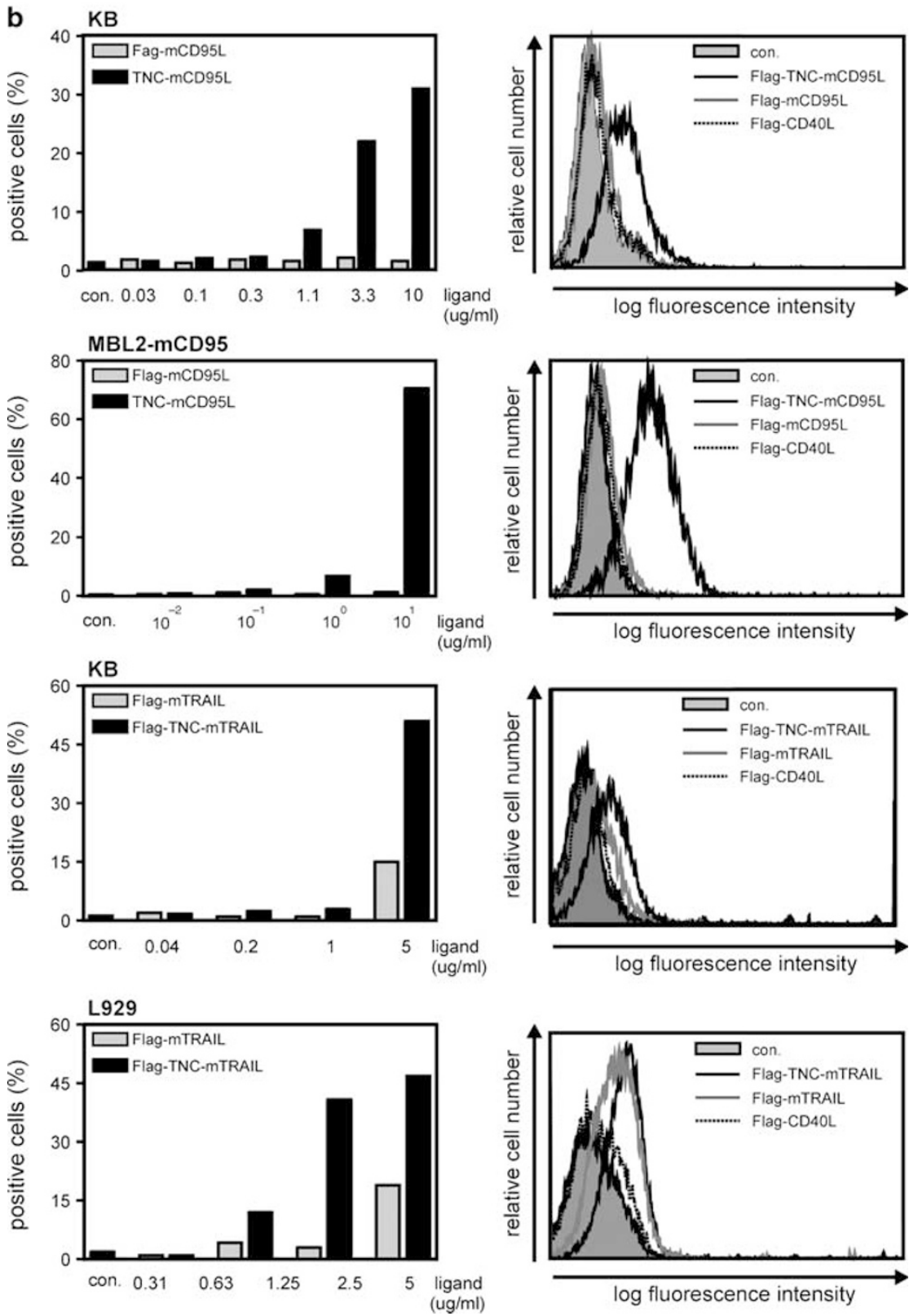

Figure 6 Continued 

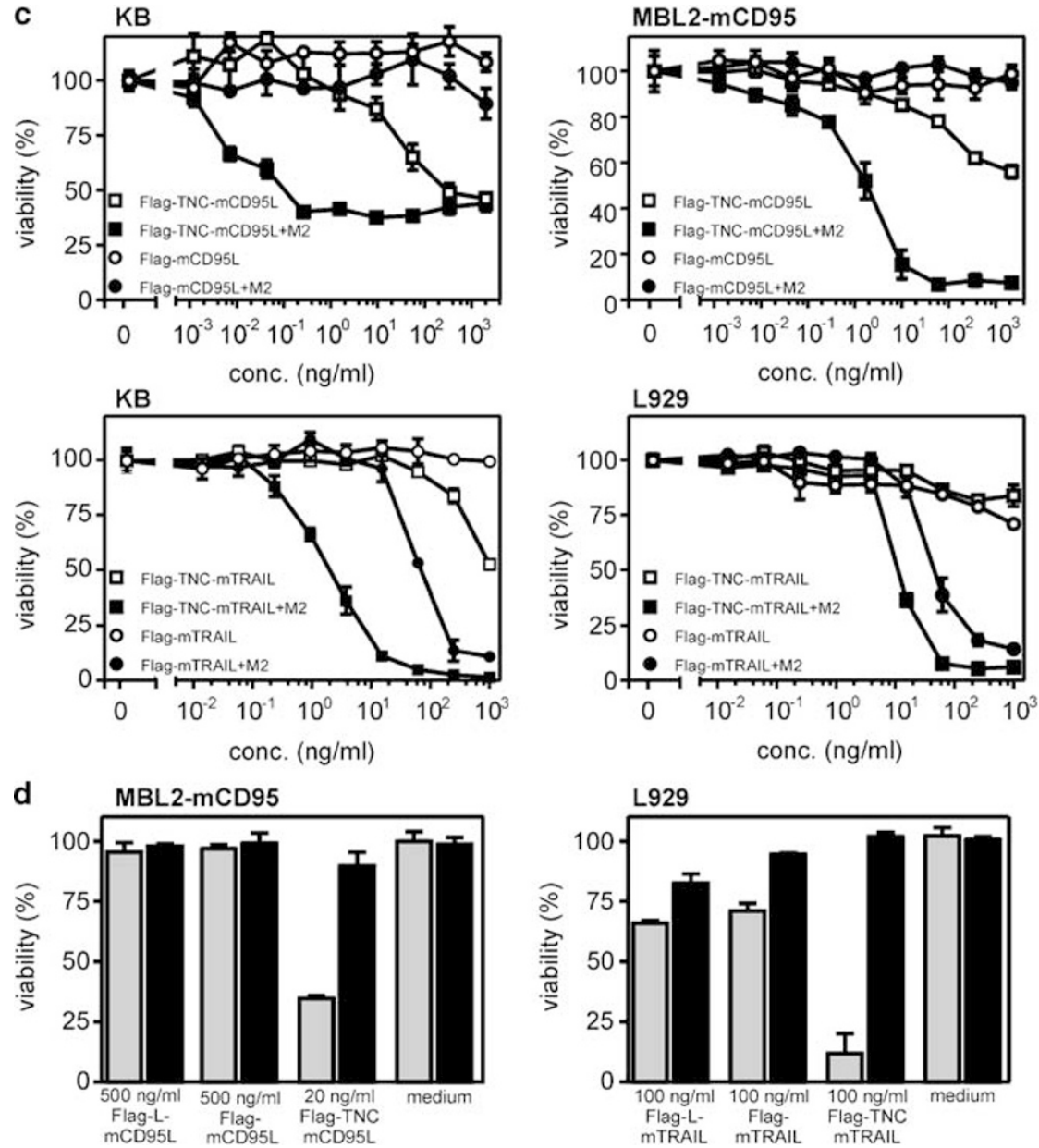

Figure 6 TNC-fusion proteins of the THD of mCD95L and mTRAIL interact with their corresponding receptors and stimulate CD95 and TRAILR2 after secondary crosslinking. (a) N-terminally Flag-tagged soluble TNC-fusion proteins of mCD95L (Flag-TNC-mCD95L(137-279)) and mTRAlL (Flag-TNC-mTRAIL(99-291)) and their corresponding 'TNC-less' variants were produced in HEK293 cells, purified by M2 affinity chromatography and analyzed under reducing and non-reducing conditions by SDSPAGE and silver staining. (b) The indicated cell lines were incubated with varying concentrations of Flag-mCD95L(137-279), Flag-TNC-mCD95L(137-279) (KB, MBL2CD95), Flag-mTRAIL(99-291), and Flag-TNC-mTRAIL(99-291) (KB, L929) on ice and after repeated washes, bound proteins were detected by FACS using anti-Flag mAb M2 and PE-labeled anti mouse IgG. A soluble N-terminally Flag-tagged variant of human CD40L served as a control. (c) KB, L929, and MBL2-mCD95 cells were seeded in triplicates in 96-well plates. The next day, cells (KB and L929) were treated with $2.5 \mu \mathrm{g} / \mathrm{ml} \mathrm{CHX}$ and were challenged (KB, L929, and MBL2-mCD95) with the indicated concentrations of Flag-mCD95L(137-279), Flag-TNC-mCD95L(137-279) (KB, MBL2-CD95 Flag-mTRAIL(99-291) (KB, L929), and Flag-TNC-mCD95L(137-279) (KB, L929) in the presence and absence of anti-Flag mAb M2 (CD95 variants: $0.5 \mu \mathrm{g} / \mathrm{ml}$; TRAlL variants $3 \mu \mathrm{g} / \mathrm{ml})$. After $18 \mathrm{~h}$ cell viability was determined by crystal violet staining. (d) MBL2-mCD95 and L929 cells were challenged in triplicates as indicated with Flag-linker, Flag, and Flag-TNC variants of murine CD95L and TRAIL in the presence (gray bars) or absence (black bars) of anti-Flag mAb M2. After overnight incubation, cell viability was determined by crystal violet staining (KB). L929 cells were treated in the presence of $2.5 \mu \mathrm{g} / \mathrm{ml} \mathrm{CHX}$

achieved by the TNC domain and (ii) secondary aggregation of THD trimers enabling CD95 activation, a function not achieved by the TNC domain. However, the functions fulfilled by the stalk region are dependent on the ligand regarded and might be realized in concert with the transmembrane domain. For example, the stalk region of hCD95L is dispensable for receptor binding, but mediates to some extent secondary aggregation and the stalk region of mTRAIL seems to stabilize the THD comprising trimer, but does not overcome the need of secondary aggregation for receptor activation.

Fusion proteins of the trimerization domain of TNC and the THD of hTRAIL or hCD95L display higher activity than their TNC less counterparts. To test whether spatial fixation of the THD also improves receptor binding and activity of soluble variants of hTRAIL (Flag-hTRAIL(95-291)) and hCD95L (Flag-hCD95L(137-281)), we generated and analyzed the corresponding TNC-fusion proteins (Flag-TNChCD95L(137-281) and Flag-TNC-hTRAIL(95-291), Figure 7a). Cross-linking experiments with $\mathrm{BS}^{3}$ and gel filtration analysis indicated that Flag-TNC-hCD95L(137-281) and Flag-TNC-hTRAIL(95-291) assemble into trimers (Figure 4 and Table 1). FACS analysis further showed that both TNC-fusion proteins were somewhat more efficient (3-10fold) than their TNC-less counterparts in receptor binding (Figure 7b). Flag-TNC-hCD95L(137-281) showed a 5- to 30 fold lower ED50 value for induction of cell death, compared to Flag-hCD95L(137-281). Non-crosslinked Flag-TNC-hTRAIL (95-291) showed regularly approximately fivefold lower $\mathrm{ED}_{50}$ 
values for apoptosis induction than its TNC-less counterpart. With respect to the capability to induce cell death after cross-linking, however, the differences were much more pronounced with 100- to 200-fold lower $E_{50}$ values for Flag-TNC-hTRAIL(95-291) (Figure 7c). The need for ligand cross-linking to activate human TRAILR2 is also required for

a
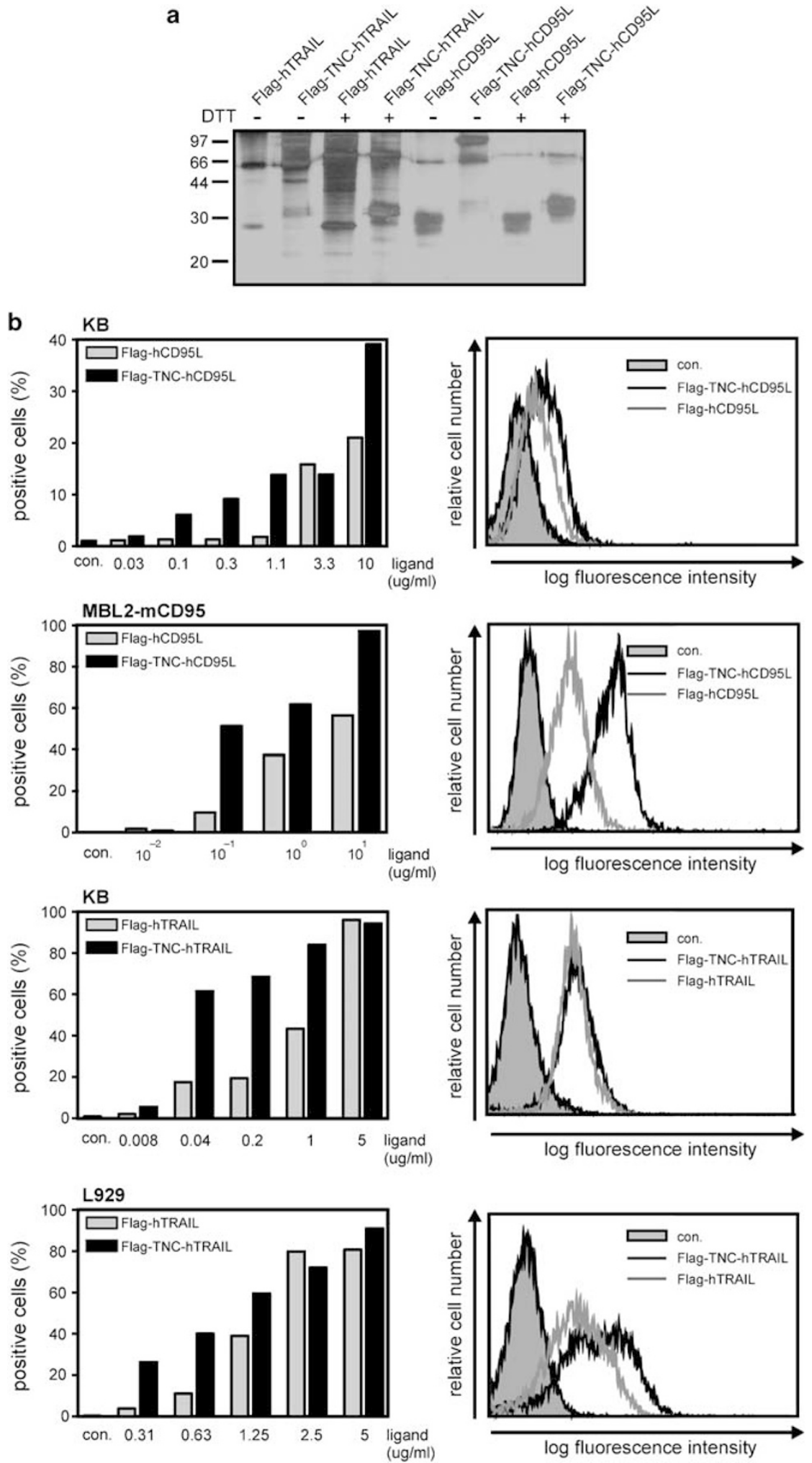

Figure 7 Continued 

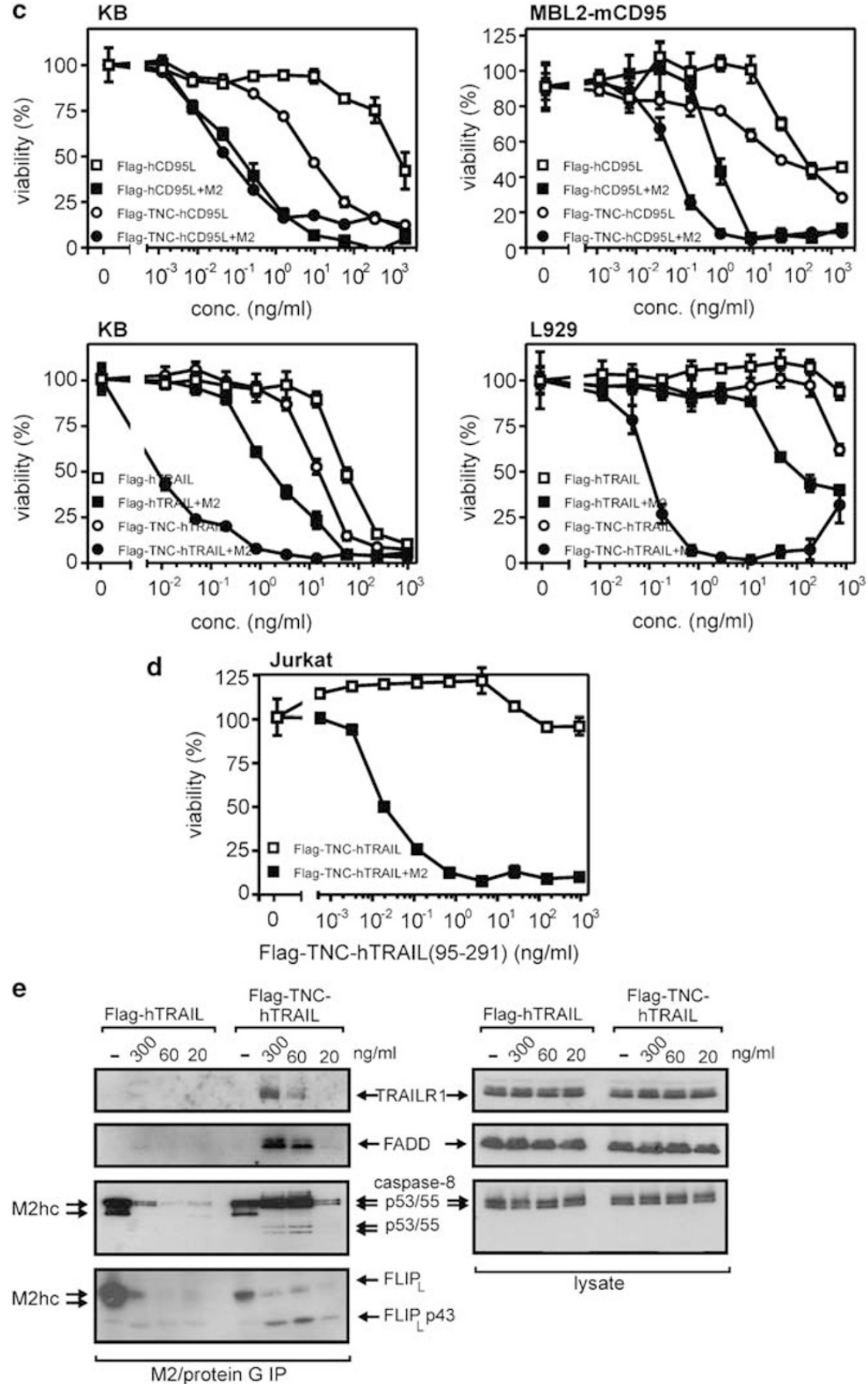

Figure 7 TNC-fusion proteins of soluble hCD95L and hTRAIL display improved receptor binding and higher activity after secondary cross-linking. (a) N-terminally Flagtagged soluble TNC-fusion proteins of hCD95L (Flag-TNC-hCD95L(137-281)) and hTRAIL (Flag-TNC-hTRAIL(95-291)) and their 'TNC-less' counterparts were produced in HEK293 cells, purified by M2 affinity chromatography and analyzed under reducing and non-reducing conditions by SDS-PAGE and silver staining. (b) The indicated cell lines were incubated with varying concentrations of Flag-hCD95L(137-281), Flag-TNC-hCD95L(137-281)) (KB, MBL2-CD95), Flag-hTRAIL(95-291), and Flag-TNC-hTRAIL(95291) (KB, L929) on ice and after repeated washing, bound proteins were detected by FACS using anti-Flag mAb M2 and PE-labeled anti mouse IgG. (c) KB, L929, and MBL2mCD95 cells were seeded in triplicates in 96-well plates. The next day, the MBL2-CD95 cells and CHX-sensitized KB and L929 cells were stimulated for $18 \mathrm{~h}$ with the indicated concentrations of Flag-hCD95L(137-281), Flag-TNC-hCD95L(137-281) (KB, MBL2-CD95), Flag-hTRAIL(95-291) (KB, L929), and Flag-TNC-hTRAIL(95-291) (KB, L929) in the presence and absence of anti-Flag mAb M2 $(0.5 \mu \mathrm{g} / \mathrm{ml})$. Cell viability was finally determined by crystal violet staining. (d) Jurkat cells were challenged in triplicates in $96-$ well plates with the indicated concentration of Flag-TNC-hTRAIL(95-291) or M2-cross-linked Flag-TNC-hTRAIL(95-291). Cell viability was determined, using the MTT assay. (e) $\mathrm{KB}$ cells were sensitized for apoptosis induction by treatment with $2.5 \mu \mathrm{g} / \mathrm{ml} \mathrm{CHX}$ for $1 \mathrm{~h}$ and were then stimulated for an additional hour with the indicated concentration of M2-cross-linked Flag-TNC-hTRAIL(95-291) or Flag-hTRAIL(95-291). The DISC was then precipitated, using protein G-Sepharose. The precipitates as well as total cell lysates were analyzed for the presence of indicated proteins by Western blotting. Lysates of untreated cells supplemented with a mixture of $10 \mathrm{ng}$ of the corresponding ligand and $50 \mathrm{ng} \mathrm{M2}$ were immunoprecipitated as controls and are indicated with '-'. Due to the excess of M2 antibody used in the control lysates, cross-reactivity with the heavychain part of the molecule is observable in the control lanes of some Western blots 
Flag-TNC-hTRAIL(95-291), as apoptosis induction in Jurkat cells expressing, which express no TRAILR1, is still strictly dependent on cross-linking (Figure 7d). In accordance with the higher activity of Flag-TNC-hTRAIL(95-291), DISC formation was also more efficient with this variant, compared with Flag-hTRAIL(95-291) (Figure 7e). It is intriguing that Flag-TNC-hTRAIL(95-291) showed a comparably less increase in receptor binding and a moderate increase in apoptosis induction (as non-crosslinked molecule) compared to Flag-hTRAIL(95-291), but a marked increase in cell death induction under crosslinked conditions. The differential relevance of the TNC domain for different properties of Flag-TNC-hTRAIL(95-291) and Flag-hTRAIL(95-291) is not clear yet, but could be related to two obvious points. First, the importance of the TNC domain for receptor binding could be receptor specific. As KB and $L 929$ cells express not only the TRAIL death receptors, but also the TRAIL decoy receptors, it cannot be ruled out that latter binds quite well to the TNC-less TRAIL variant masking a more pronounced effect on binding to the TRAIL death receptors. Furthermore, in the human system TRAILR1 and TRAILR2, which are differentially dependent on ligand cross-linking for activation, are also differentially regulated by TRAILR4. ${ }^{19,20}$ Second, the transformation of receptor occupancy by ligand into DISC formation and further to activation of apoptotic caspases could be non-linear and receptor-specific.

Taken together, fusion with the TNC domain did not overcome the requirement of hCD95L and hTRAIL for secondary cross-linking to become properly active (Figure 7c and d). This is in agreement with the fact that the TNC domain does not mediate secondary aggregation of ligand trimers. Thus, the introduction of a TNC domain appears to be a broadly applicable option to generate recombinant soluble ligands of the TNF family with superior activity.

\section{Materials and Methods}

Plasmids and cell lines. All expression plasmids encoding the proteins summarized in Figure 1 were constructed based on the PS435 plasmid, which is a modification of pCR3 (Invitrogen, Karlsruhe, Germany) encoding N-terminally Flagtagged TRAILR2 with an immunoglobulin signal peptide. ${ }^{21}$ PS435 was a kind gift from Pascal Schneider (University of Lausanne, Epalinges, Switzerland). To obtain the pCR3-derived expression plasmids encoding the various TRAIL and CD95L fusion proteins, the indicated domains of hTRAIL (U37518), mTRAIL (NM_009425), hCD95L (U11821) and murine CD95L (NM 010177) were amplified with primers having $5^{\prime}$ overhangs containing a EcoR1 site and $3^{\prime}$ overhangs containing a Xba1 or Xho1 site and used to replace the TRAILR2 part of PS435. To obtain expression plasmids encoding the TNC counterparts of the resulting Flag-tagged TRAIL and CD95L variants, the Flag tag-encoding DNA fragment was removed using the flanking BamH1 and EcoR1 sites and replaced by a corresponding amplicon encoding the Flag tag and aa 110-139 of chicken TNC (M23121). To obtain the expression plasmids, encoding Flag-L-mCD95L(137-279) and Flag-L-mTRAIL(99291), the CDNA part encoding the TNC domain was replaced by a linker encoding a similar number of amino acids. MBL2-mCD95 cells are a kind gift from JP Medema (Academic Medical Center, Amsterdam, Netherlands) and have been described elsewhere. ${ }^{22}$

Production and purification of recombinant proteins. The different plasmids encoding the various TRAIL and CD95L variants were transfected in HEK293 by electroporation. A total of $40 \times 10^{6}$ HEK293 cells, suspended in $1 \mathrm{ml}$ RPMI supplemented with $10 \%$ FCS, were electroporated $4 \mathrm{~mm}$ cuvette, $250 \mathrm{~V}$ $1800 \mu \mathrm{F}$, maximal resistance) with $30 \mu \mathrm{g}$ of plasmid DNA. Cells were recovered overnight in $15 \mathrm{~cm}$ dishes with RPMl $/ 10 \% \mathrm{FCS}$. The next day, medium was changed with low serum medium $(0.5 \%$ FCS) and supernatants were collected after additional 3-4 days. Supernatants were concentrated by dialysis on PEG35000 and the recombinant proteins were purified by affinity chromatography using an antiFlag mAb M2 agarose column (Sigma). The bound proteins were eluted with $100 \mu \mathrm{g} / \mathrm{ml}$ Flag peptide (Sigma) and dialyzed against PBS to remove the majority of the Flag peptide. Purified proteins were quantified by BCA (Pierce) and/or by comparison with a flag-tagged protein standard by Western blotting. Concentrations of non-tagged variants of MTRAIL and CD95L were determined by Western blot comparison using rat anti-mTRAIL mAb N2B2, a kind gift from Professor Yagita (Juntendo University School of Medicine, Tokyo, Japan), and goat anti-hCD95L IgG (RD Systems, Wiesbaden, Germany) mAbs samples with their Flag-tagged counterparts at known concentrations. Fc-hTRAIL and Fc-hCD95L are fusion proteins containing the constant region of human IgG1 and the THD of hTRAIL and hCD95L, respectively. Both proteins were kindly prepared by Victoria Schäfer (University of Wuerzburg, Germany).

Flow cytometry with recombinant TRAIL and CD95L variants. Cells were incubated for $30 \mathrm{~min}$ at $4^{\circ} \mathrm{C}$ with the indicated concentration of the various variants of CD95L or TRAIL. After washing the cells three times with PBS containing $0.5 \%$ bovine serum albumin (BSA; Sigma), cells were incubated with $5 \mu \mathrm{g} / \mathrm{ml}$ anti-Flag mAb M2 (Sigma) for $30 \mathrm{~min}$ at $4^{\circ} \mathrm{C}$. After washing three times with PBS/BSA the cell-bound fusion protein-antibody complexes were detected using PE-conjugated goat anti-mouse IgG (whole molecule) lgG.

Chemical cross-linking with BS3. The various variants of CD95L or TRAIL (200 ng) were incubated with varying concentrations of the chemical crosslinker bis(sulfosuccinimidyl)suberate (BS ${ }^{3}$; Pierce) for $30 \mathrm{~min}$ on ice in a total volume of $40 \mu \mathrm{l}$. The cross-linking reaction was stopped by quenching with $2 \mu \mathrm{l}$ of $1 \mathrm{M}$ Tris- $\mathrm{HCl}, \mathrm{pH}$ 7.5. Finally, the crosslinked proteins were separated by SDS-PAGE and analyzed by anti-Flag Western blot.

Vitality assays. The various cell lines (KB, L929, MBL2-CD95: $20 \times 10^{3} /$ well; Jurkat $50 \times 10^{3} /$ well) were cultured in $100 \mu$ l of culture medium in 96 -well plates. The Next day, cells were treated in triplicates with the indicated concentrations of the various variants of CD95L or TRAIL in the presence and absence of the crosslinking $0.5 \mu \mathrm{g} / \mathrm{ml}$ anti-Flag mAb M2. Holler et al. ${ }^{7}$ have previously shown that antiFlag-induced multimerization becomes suboptimal at higher ligand concentrations. In our experiments, this becomes evident especially when TRAIL variants were used. We therefore used, in some experiments with TRAIL proteins, $3 \mu \mathrm{g} / \mathrm{ml}$ of anti-Flag M2 for cross-linking to induce apoptosis. After $20 \mathrm{~h}$, cell viability was determined by crystal violet staining (KB, L929, MBL2-CD95) or the MTT assay (Jurkat). To sensitize KB and L929 cells for induction of cell death, these cells were stimulated in the presence of $2.5 \mu \mathrm{g} / \mathrm{ml}$ cycloheximide (Sigma).

Silver staining. Approximately $250 \mathrm{ng}$ of the affinity-purified proteins was separated by $16 \%$ SDS-PAGE using reducing and non-reducing Laemmli sample buffer. After incubation twice with fixer (40\% methanol, $12 \%$ acetic acid) for $30 \mathrm{~min}$ and washing twice with $30 \%$ ethanol, gels were treated with $0.02 \%$ (w/v) sodium thiosulfate for $1 \mathrm{~min}$. After three times washing for $30 \mathrm{~s}$ in distilled $\mathrm{H}_{2} \mathrm{O}$ and incubation for $20 \mathrm{~min}$ in $0.2 \%$ (w/v) silver nitrate solution freshly supplemented with formaldehyde $(1: 333)$, gels were washed again in $\mathrm{ddH}_{2} \mathrm{O}$ (three times for $1 \mathrm{~min}$ ) and were finally developed with $6 \%(\mathrm{w} / \mathrm{v})$ sodium carbonate freshly supplemented with formaldehyde $(1: 500)$ and $0.0004 \%(w / v)$ sodium thiosulfate. When the desired signal intensity was achieved the developer was discarded and the reaction was stopped with $5 \%$ acetic acid.

Gel filtration. Protein samples were applied either to a BioSep-SEC-S2000 $(300 \times 7.8)$ column or to a BioSep-SEC-S3000 $(300 \times 7.8)$ column (Phenomenex, Aschaffenburg, Germany) equilibrated in PBS and eluted at a flow rate of $0.5 \mathrm{ml} / \mathrm{min}$.

DISC analysis. DISC analysis with Flag-TNC-hTRAIL(95-291) and FlaghTRAIL(95-291) were performed as described recently elsewhere. ${ }^{23}$ Antibodies used to detect FADD, FLIP, TRAILR1, and caspase-8 were purchased from BD (Heidelberg, Germany; FADD) and Axxora (Grünberg, Germany; TRAILR1 and FLIP) or was a kind gift from K Schulze-Osthoff (University of Düsseldorf, Germany; anti-caspase-8 $\mathrm{mAb}$ ). 
Surface plasmon resonance analysis of CD95L-CD95 interaction. Dissociation constants $\left(\mathrm{K}_{\mathrm{D}}\right)$ for the binding of Flag-hCD95L(137281), Flag-mCD95L(137-279) and Flag-TNC-mCD95L(137-279) to an immobilized fusion protein of hlgG1 and the extracellular domain of human CD95 (FC-CD95) were calculated from surface plasmon resonance measurements (BIAcore 2000, Pharmacia). Fc-CD95 was biotinylated and coupled with $1 \mu \mathrm{g} / \mathrm{ml}$ to the surface of a streptavidin-coated sensor chip (Pharmacia) as described elsewhere. ${ }^{24}$ Sensorgrams were recorded for binding of the various ligands at concentrations ranging from 2 ( $\mathrm{hCD} 95 \mathrm{~L})$ or $5 \mathrm{nM}$ (mCD95L variants) to 1000 and $5000 \mathrm{nM}$, respectively. The kinetic constants $\left(k_{\mathrm{d}}\right.$ and $\left.k_{\mathrm{a}}\right)$ were determined using a $1: 1$ binding model and the software supplied by the manufacturer and were used to calculate the dissociation constant

Acknowledgements. This work was supported by Deutsche Krebshilfe (Grant no 10-1751-Wa 3), Wilhelm-Sander-Stiftung (Grant no 2003.120.1), Deutsche Forschungsgemeinschaft (SFB 487 project B7) and IZKF Wuerzburg (project B-32).

1. Locksley RM, Killeen N, Lenardo MJ. The TNF and TNF receptor superfamilies: integrating mammalian biology. Cell 2001; 104: 487-501.

2. Bodmer JL, Schneider P, Tschopp J. The molecular architecture of the TNF superfamily. Trends Biochem Sci 2002; 27: 19-26.

3. Grell M, Douni E, Wajant H, Lohden M, Clauss M, Maxeiner B et al. The transmembrane form of tumor necrosis factor is the prime activating ligand of the $80 \mathrm{kDa}$ tumor necrosis factor receptor. Cell 1995; 83: 793-802.

4. Schneider P, Holler N, Bodmer JL, Hahne M, Frei K, Fontana A et al. Conversion of membrane-bound Fas(CD95) ligand to its soluble form is associated with downregulation of its proapoptotic activity and loss of liver toxicity. J Exp Med 1998; 187: 1205-1213.

5. Wajant $\mathrm{H}$, Moosmayer D, Wuest $\mathrm{T}$, Bartke $\mathrm{T}$, Gerlach $\mathrm{E}$, Schonherr $\mathrm{U}$ et al. Differential activation of TRAIL-R1 and - 2 by soluble and membrane TRAIL allows selective surface antigen-directed activation of TRAIL-R2 by a soluble TRAIL derivative. Oncogene 2001; 20: 4101-4106.

6. Haswell LE, Glennie MJ, Al-Shamkhani A. Analysis of the oligomeric requirement for signaling by CD40 using soluble multimeric forms of its ligand, CD154. Eur J Immunol 2001; 31: 3094-3100.

7. Holler N, Tardivel A, Kovacsovics-Bankowski M, Hertig S, Gaide O, Martinon F et al. Two adjacent trimeric Fas ligands are required for Fas signaling and formation of a deathinducing signaling complex. Mol Cell Biol 2003; 23: 1428-1440.

8. Stone GW, Barzee S, Snarsky V, Kee K, Spina CA, Yu XF et al. Multimeric soluble CD40 ligand and GITR ligand as adjuvants for human immunodeficiency virus DNA vaccines. $J$ Virol 2006; 80: 1762-1772.

9. Mundle SD, Raza A. Defining the dynamics of self-assembled Fas-receptor activation. Trends Immunol 2002; 23: 187-194.
10. Siegel RM, Muppidi JR, Sarker M, Lobito A, Jen M, Martin D et al. SPOTS: signaling protein oligomeric transduction structures are early mediators of death receptor-induced apoptosis at the plasma membrane. J Cell Biol 2004; 167: 735-744.

11. Henkler F, Behrle E, Dennehy KM, Wicovsky A, Peters N, Warnke C et al. The extracellular domains of FasL and Fas are sufficient for the formation of supramolecular FasL-Fas clusters of high stability. J Cell Biol 2005; 168: 1087-1098.

12. Schneider P, Bodmer JL, Holler N, Mattmann C, Scuderi P, Tersikikh A et al Characterization of Fas (Apo-1, CD95)-Fas ligand interaction. J Biol Chem 1997; 272: 18827-18833.

13. Muhlenbeck F, Schneider P, Bodmer JL, Schwenzer R, Hauser A, Schubert G et al. The tumor necrosis factor-related apoptosis-inducing ligand receptors TRAIL-R1 and TRAIL-R2 have distinct cross-linking requirements for initiation of apoptosis and are non-redundant in JNK activation. J Biol Chem 2000; 275: 32208-32213.

14. Kelley RF, Totpal K, Lindstrom SH, Mathieu M, Billeci K, Deforge L et al. Receptor-selective mutants of apoptosis-inducing ligand 2/tumor necrosis factor-related apoptosis-inducing ligand reveal a greater contribution of death receptor (DR) 5 than DR4 to apoptosis signaling. J Biol Chem 2005; 280: 2205-2212.

15. Wu GS, Burns TF, Zhan Y, Alnemri ES, El-Deiry WS. Molecular cloning and functional analysis of the mouse homologue of the KILLER/DR5 tumor necrosis factor-related apoptosis-inducing ligand (TRAIL) death receptor. Cancer Res 1999; 59: 2770-2775.

16. Schneider P, Olson D, Tardivel A, Browning B, Lugovskoy A, Gong D et al. Identification of a new murine tumor necrosis factor receptor locus that contains two novel murine receptors for tumor necrosis factor-related apoptosis-inducing ligand (TRAIL). J Biol Chem 2003; 278: $5444-5454$.

17. Suda T, Tanaka M, Miwa K, Nagata S. Apoptosis of mouse naive T cells induced by recombinant soluble Fas ligand and activation-induced resistance to Fas ligand. J Immunol 1996; 157: 3918-3924.

18. Kammerer RA, Schulthess $T$, Landwehr R, Lustig A, Fischer D, Engel J. Tenascin-C hexabrachion assembly is a sequential two-step process initiated by coiled-coil alphahelices. J Biol Chem 1998; 273: 10602-10608.

19. Clancy L, Mruk K, Archer K, Woelfel M, Mongkolsapaya J, Screaton G et al. Preligand assembly domain-mediated ligand-independent association between TRAlL receptor 4 (TR4) and TR2 regulates TRAIL-induced apoptosis. Proc Natl Acad Sci USA 2005; 102 18099-18104.

20. Mérino D, Lalaoui N, Morizot A, Schneider P, Solary E, Micheau O. Differential inhibition of TRAIL-mediated DR5-DISC formation by decoy receptors 1 and 2. Mol Cell Biol 2006; 26 : 7046-7055

21. Schneider P, Thome M, Burns K, Bodmer JL, Hofmann K, Kataoka T et al. TRAIL receptors 1 (DR4) and 2 (DR5) signal FADD-dependent apoptosis and activate NF-kappaB. Immunity 1997; 7: 831-836.

22. Medema JP, de Jong J, van Hall T, Melief CJ, Offringa R. Immune escape of tumors in vivo by expression of cellular FLICE-inhibitory protein. J Exp Med 1999; 190: 1033-1038.

23. Siegmund D, Klose S, Zhou D, Baumann B, Röder C, Kalthoff $\mathrm{H}$ et al. Role of caspases in CD95L- and TRAIL-induced non-apoptotic signalling in pancreatic tumour cells. Cell Signal 2007: 19: 1172-1184.

24. Shen BJ, Hage T, Sebald W. Global and local determinants for the kinetics of interleukin-4/ interleukin-4 receptor alpha chain interaction. A biosensor study employing recombinan interleukin-4-binding protein. Eur J Biochem 1996; 240: 252-261. 